\title{
Synthesis of fluorescent $\boldsymbol{O}$-Coumarin glycosides as Potential drug delivery systems for MAO inhibitors
}

\author{
Antonio Franconetti,* Óscar López, Pastora Borrachero, José G. Férnandez-Bolaños and \\ Francisca Cabrera-Escribano
}

Departamento de Química Orgánica, Facultad de Química, Universidad de Sevilla, C/ Profesor García González, 141012 Seville, Spain; Tel: +34954556868.

*E-mail: afranconetti@us.es

\begin{abstract}
MAO inhibitors have increased their importance as a result of the high incidence of neurodegenerative diseases such as Parkinson or Alzheimer. Herein, we report the synthesis and characterization of coumarin glycosides by reaction of a glycosyl halide with coumarin derivatives as well as mechanistic considerations based on DFT calculations. Additionally, the determination of the enzymatic parameters has shown that the carbohydrate-coumarin derivative is an efficient drug-releasing system.
\end{abstract}

\section{Keyword}

Coumarins, carbohydrates, MAO inhibitors, neurodegenerative diseases

\section{Introduction}

Nowadays, the high prevalence and incidence ${ }^{1}$ of neurodegenerative diseases, such as Parkinson, Alzheimer or amyotrophic lateral sclerosis diseases makes an important field to search for novel molecules to access different customized treatment. In this context, monoaminooxidase (MAO) inhibitors have been used for this purpose in the initial stage of Parkinson's disease. ${ }^{2}$

In nature, two isoenzymes of MAO (MAO A and $\mathrm{B}$ ) are described and located in the most of mammalian tissues. ${ }^{3,4}$ However, both enzymes present different tissue distribution, physiological function and substrate specificity. These isoforms act on a variety of endogenous and exogenous amine derivatives as neurotransmitters. ${ }^{5}$ For this reason, their inhibitions can involve an enhancement of neurotransmitters (i.e. dopamine) in cellular medium.

Coumarins have demonstrated to provide a wide range of biological activities including MAO inhibitor capability. ${ }^{6}$ Additionally, this kind of compounds shows fluorescent properties that improving its detection at physiological environments. However, these 
compounds often suffer from poor solubility. With the aim of solving this drawback, following the strategy carrier pro-drug, coumarin attachment to a carbohydrate residue allowed us to improve this disadvantage.

In this communication we report the synthesis of coumarinyl glycosides by reaction of a glycosyl halide with coumarin derivatives and their characterization. The reaction has been optimized to achieve good selectivities and yields. For this purpose, mechanistic considerations based on DFT calculations have been also performed. In addition, the determination of the enzymatic parameters has shown that the carbohydrate-coumarin derivative is an efficient drug-releasing system.

\section{Experimental Methods}

All chemicals were purchased and used without further purification. Evaporations were conducted under reduced pressure. TLC was performed on silica gel plates (DCAlufolien $\mathrm{F}_{254}$, E. Merck). All new compounds were synthesized following the general procedure. Detection of compounds was accomplished with UV light (254 nm) and by charring with $\mathrm{H}_{2} \mathrm{SO}_{4}$ and characterization by ${ }^{1} \mathrm{H}$ and ${ }^{13} \mathrm{C}$ NMR spectroscopy and Mass spectrometry.

\section{General Procedure for glycosylation reactions}

To a solution of glycosyl bromide (1 equiv.) in MeCN (45 mL) was succesively added coumarin derivative (1.2 equiv.) and $\mathrm{H}_{2} \mathrm{O}(500 \mu \mathrm{L})$. Then, $\mathrm{K}_{2} \mathrm{CO}_{3}$ (1.2 equiv.) was added to the reaction mixture. The heterogeneous reaction mixture was stirred at $60{ }^{\circ} \mathrm{C}$ for $1 \mathrm{~h}$ monitoring by TLC. The reaction was filtered off a celite pad and concentrated under reduced pressure. The residue was dissolved in DCM $(40 \mathrm{~mL})$ and washed with 2 $\mathrm{M} \mathrm{NaOH}(3 \times 40 \mathrm{~mL})$. The organic layer was dried with $\mathrm{Na}_{2} \mathrm{SO}_{4}$ and concentrated. Recrystallization from $\mathrm{MeOH}$ gave the coumarinyl glycoside in acceptable yield.

Spectral data for compound 3: ${ }^{1} \mathrm{H} \mathrm{RMN}\left(300 \mathrm{MHz}, \mathrm{CDCl}_{3}, \delta \mathrm{ppm}\right): \delta 7.65\left(1 \mathrm{H}, \mathrm{d}, J_{4}, 3^{\prime}\right.$ $\left.9.6 \mathrm{~Hz}, \mathrm{H}-4^{\prime}\right), 7.40$ (1H, d, $\left.J_{5}^{\prime}, 6,8.5 \mathrm{~Hz}, \mathrm{H}-5^{\prime}\right), 6.96$ (1H, d, $\left.J_{8^{\prime}, 6^{\prime}} 2.0 \mathrm{~Hz}, \mathrm{H}-8^{\prime}\right), 6.91$ $\left(1 \mathrm{H}, \mathrm{dd}, J_{6^{\prime}, 8^{\prime}} 2.3, J_{6^{\prime}, 5}, 8.5 \mathrm{~Hz}, \mathrm{H}-6^{\prime}\right), 6.32\left(1 \mathrm{H}, \mathrm{d}, J_{3^{\prime}, 4}, 9.5 \mathrm{~Hz}, \mathrm{H}-3^{\prime}\right), 5.33-5.27$ (2H, m, H-1 y H-3), 5.20-5.13 (2H, m, H-2 y H-4), 4.29 (1H, dd, $\left.J_{6,5} 5.7, J_{6,6}, 12.3 \mathrm{~Hz}, \mathrm{H}-6\right)$, $4.19\left(1 \mathrm{H}, \mathrm{dd}, J_{6,}{ }_{, 5} 2.1, J_{6 ",}{ }_{6} 12.3 \mathrm{~Hz}, \mathrm{H}-6\right.$ ' $), 3.92$ (1H, m, H-5), 2.11 (3H, s, OCOCH ${ }_{3}$ ), $2.07\left(6 \mathrm{H}, \mathrm{s}, \mathrm{OCOCH}_{3}\right), 2.04\left(3 \mathrm{H}, \mathrm{s}, \mathrm{OCOCH}_{3}\right)$. 


\section{Results and discussion}

Synthesis of coumarinyl glycosides (3-6) were prepared following the experimental procedure described above from acetobromo- $\alpha$-D-glucose (1) used as acceptor (Scheme $1)$.

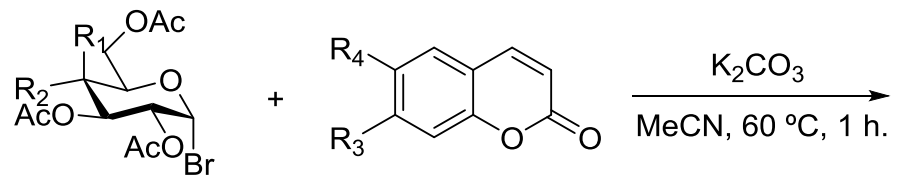

1: $R_{1}=H, R_{2}=O A C$

2: $R_{1}=O A c, R_{2}=H$

$$
\begin{aligned}
& \mathrm{R}_{3}=\mathrm{OH}, \mathrm{R}_{4}=\mathrm{H} \\
& \mathrm{R}_{3}=\mathrm{H}, \mathrm{R}_{4}=\mathrm{OH}
\end{aligned}
$$

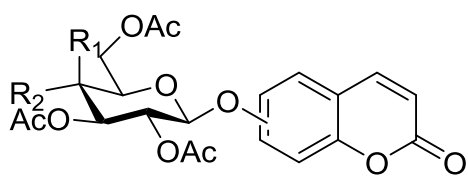

3: $\mathrm{R}_{1}=\mathrm{H}, \mathrm{R}_{2}=\mathrm{OAC}, \mathrm{R}_{4}=\mathrm{H}$

4: $\mathrm{R}_{1}=\mathrm{OAc}, \mathrm{R}_{2}=\mathrm{H}, \mathrm{R}_{4}=\mathrm{H}$

5: $R_{1}=H, R_{2}=O A c, R_{3}=H$

6: $R_{1}=O A c, R_{2}=H, R_{3}=H$ $\mathrm{NaOMe}$
$\mathrm{MeOH}$

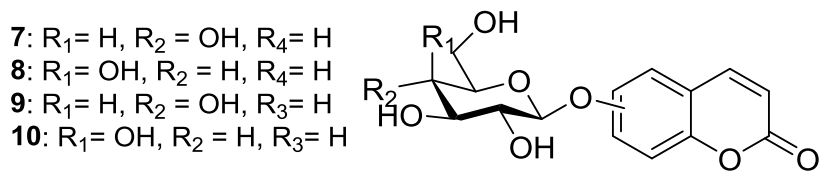

Scheme 1

Previously, an optimization of reaction conditions was performed in order to obtain the desired coumarinyl glycoside instead of elimination byproduct $\mathbf{1 1}$ which synthesis is mediated by unexpected dehydrohalogenation in the reaction medium. For this purpose, several modifications of base, solvent, additive and temperature were realized. Coupling constant measured $\left(J_{1,2} \sim 8.0 \mathrm{~Hz}\right)$ in ${ }^{1} \mathrm{H}$ NMR spectrum exclusively shows the selective formation of $\beta$ anomer.

Additionally, DFT calculations by using B3LYP 6-31G level of theory include in GAMESS package were also applied to understand electronic and steric factors which govern the glycosylation reaction. Results bring to light two intermediates (II and III, Scheme 2) for each reaction pathway, respectively. Taking into account the corresponding energies $(\mathrm{G}, \mathrm{kJ} / \mathrm{mol})$ elimination byproduct was more stable than desired glycoside. This fact could clearly explain our experimental results. 


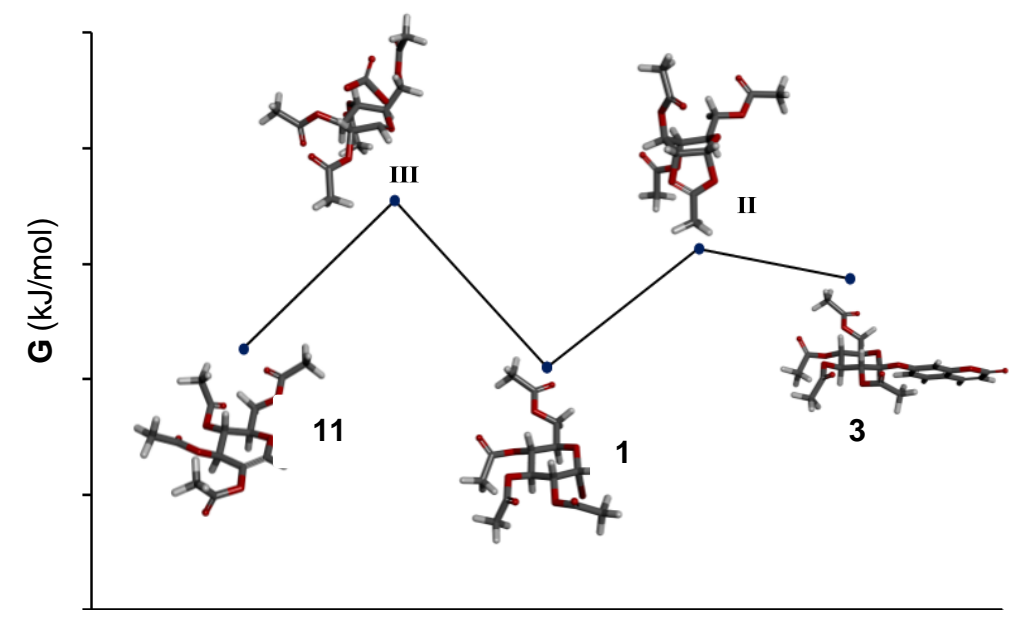

Reaction coordinate

Scheme 2

Finally, enzymatic molecular recognition was explored by using enzymatic and docking studies. With the aim to simulate in vivo delivery by endogenous enzyme, MichaelisMenten costants $\left(K_{\mathrm{m}}\right)$ for deprotected glycosidases (7-10) were determined from HanesWoolf plots. For docking ${ }^{7}$ simulation a pre optimized structure for coumarinyl Dgalactoside with B3LYP 6-31G (d,p) was used.

\section{Conclusions}

An efficient and easy route to access to carbohydrate-coumarin systems have been successfully carried out. Furthermore, DFT calculations prove to be essential to understand the unexpected dehydrobromination which impede an improvement on the glycosylation yield.

Docking and enzymatic assays have been performed to calculated the affinity of our system for $\beta$-glycosidases (e.g. $\mathrm{K}_{\mathrm{m}} 3.25 \mathrm{mM}$ for compound 7) providing a novel drug delivery capability of these derivatives.

\section{Acknowledgements}

We thank the AECID (Projects A/023577/09 and A/030422/10) and the 'Junta de Andalucía' (FQM 142 and Project P09-AGR-4597) for financial support. 


\section{References}

1. Neurological disorders: public health challenges. Ed.; World Health Organization, Switzerland, 2006.

2. Youdim, M. B. Edmondson, D.; Tripton, K. F. Nat. Rev. Neurosci. 2006, 7, 295-309

3. Shih, J. C.; Chen, K.; Ridd, M. J. Annu. Rev. Neurosci. 1999, 22, 197-217.

4. Tripton, K. F.; Boyce, S.; O’ Sullivan, J.; Davey, G. P. Healy, J. Curr. Med. Chem. 2004, 11, 1965-1982.

5. Wang, C. C.; Billet, E.; Borchet, A.; Kuhn, H.; Ufer, C. Cell. Mol. Life Sci. 2013, 70, 599-630.

6. Patil, P. O.; Bari, S. B.; Firke, S. D.; Deshmukh, P. K.; Donda, S. T.; Patil, D. A. Bioorg. Med. Chem. 2013, 21, 2434-2450.

7. Huang, S.-Y.; Zou, X. Int. J. Mol. Sci. 2010, 11, 3016-3034. 